\title{
Effect of Transcutaneous Electrode Temperature on Accuracy and Precision of Carbon Dioxide and Oxygen Measurements in the Preterm Infants
}

\author{
Jessica F Jakubowicz MD, Shasha Bai PhD, David N Matlock MD, Michelle L Jones DO, \\ Zhuopei Hu MSc, Betty Proffitt RRT, and Sherry E Courtney MD
}

\begin{abstract}
BACKGROUND: High electrode temperature during transcutaneous monitoring is associated with skin burns in extremely premature infants. We evaluated the accuracy and precision of $\mathrm{CO}_{2}$ and $\mathrm{O}_{2}$ measurements using lower transcutaneous electrode temperatures below $42^{\circ} \mathrm{C}$. METHODS: We enrolled 20 neonates. Two transcutaneous monitors were placed simultaneously on each neonate, with one electrode maintained at $42^{\circ} \mathrm{C}$ and the other randomized to temperatures of $38,39,40,41$, and $42^{\circ} \mathrm{C}$. Arterial blood was collected twice at each temperature. RESULTS: At the time of arterial blood sampling, values for transcutaneously measured partial pressure of $\mathrm{CO}_{2}\left(\mathrm{P}_{\mathrm{tcCO}}\right)$ were not significantly different among test temperatures. There was no evidence of skin burning at any temperature. For $\mathbf{P}_{\text {tcCO}}$, Bland-Altman analyses of all test temperatures versus $42^{\circ} \mathrm{C}$ showed good precision and low bias. Transcutaneously measured partial pressure of $\mathbf{O}_{2}\left(\mathbf{P}_{\text {tco }_{2}}\right)$ values trended arterial values but had large negative bias. CONCLUSION: Transcutaneous electrode temperatures as low as $38^{\circ} \mathrm{C}$ allow an assessment of $\mathbf{P}_{\mathrm{tcCO}_{2}}$ as accurate as that with electrodes at $42^{\circ} \mathrm{C}$. Key words: transcutaneous monitoring; carbon dioxide monitoring; oxygen monitoring; electrode temperature; blood gas monitoring. [Respir Care 2018;63(7):900-906. (c) 2018 Daedalus Enterprises]
\end{abstract}

\section{Introduction}

Extremes and fluctuations of arterial $\mathrm{CO}_{2}$ and $\mathrm{O}_{2}$ tension pose well-documented risks to the neonate, including periventricular leukomalacia, ${ }^{1-3}$ intraventricular hemorrhage, ${ }^{3-6}$ retinopathy of prematurity, ${ }^{7}$ bronchopulmonary dysplasia, and mortality. ${ }^{8-10}$

Drs Jakubowicz, Bai, Matlock, and Courtney, and Mr Hu and Ms Proffitt, are affiliated with the Department of Pediatrics, University of Arkansas for Medical Sciences, Little Rock, AR. Dr Jones is affiliated with St. John Medical Center and Hillcrest Medical Center, Tulsa, OK. At the time of this study, Dr Jones was affiliated with the Department of Pediatrics, University of Arkansas for Medical Sciences, Little Rock, AR.

The authors report partial funding for this project by an intramural grant from the UAMS College of Medicine Children's University Medical Group Grant Program, grant \#2822-3. Transcutaneous monitors were provided for this study by Radiometer, which did not have any participation in study design, data collection or statistical analysis.

Dr Jakubowicz presented a version of this article at the Pediatric Academic Societies Meeting held May 6, 2017, in San Francisco, California.
Therefore, these levels must be closely monitored. Arterial blood sampling is the accepted standard, but this provides only a single measurement of what is often a constantly changing clinical picture. It is also invasive by nature, requiring either an indwelling catheter or multiple needle sticks and can lead to anemia, which is an already prevalent issue in premature infants.

Transcutaneous monitors can provide continuous $\mathrm{CO}_{2}$ and $\mathrm{O}_{2}$ monitoring. One limitation to the widespread use of transcutaneous monitors in neonatal ICUs is the previously reported association of skin burning in extremely low birthweight infants due to the elevated electrode temperature required to achieve arterialization of the capillary bed, particularly in the measurement of $\mathrm{P}_{\mathrm{tcO}_{2}}{ }^{11-13}$ High electrode temperature may not be needed for $\mathrm{P}_{\mathrm{tcCO}}$ assessment.

Correspondence: Jessica F Jakubowicz MD, University of Arkansas for Medical Sciences, 4301 W Markham St, Slot 512-5B, Little Rock, AR 72205. E-mail: jmjakubowicz@uams.edu.

DOI: $10.4187 /$ respcare. 05887 
We hypothesized that a transcutaneous electrode temperature as low as $38^{\circ} \mathrm{C}$ would be accurate and precise in the measurement of $\mathrm{CO}_{2}$ levels. We sought (1) to assess the accuracy and precision of 4 lower electrode temperatures $\left(38,39,40,41^{\circ} \mathrm{C}\right)$ compared to the recommended temperature of $42^{\circ} \mathrm{C}$ in the measurement of $\mathrm{CO}_{2}$ levels in preterm infants between $1-2 \mathrm{~kg}$; (2) to assess the accuracy and precision of all measured electrode temperatures (38$42^{\circ} \mathrm{C}$ ) in the measurement of $\mathrm{CO}_{2}$ compared to the accepted standard, arterial blood gas $\mathrm{P}_{\mathrm{CO}_{2}}$; (3) to reassess the accuracy and precision of $\mathrm{P}_{\mathrm{tcO}_{2}}$ compared to $\mathrm{P}_{\mathrm{aO}}$ and assess $\mathrm{P}_{\mathrm{tcO}_{2}}$ at the 4 lower electrode temperatures $(38,39,40$, $\left.41^{\circ} \mathrm{C}\right)$.

\section{Methods}

\section{Subjects}

This study was approved by the Institutional Review Board of the University of Arkansas for Medical Sciences. A total of 20 neonates were enrolled after written parental consent was obtained. Inclusion criteria included birthweight $1-2 \mathrm{~kg}$, umbilical arterial access, and hematocrit levels $>35 \%$. Exclusion criteria included pressor support, hematocrit levels $<35 \%$, congenital anomalies, nitric oxide use, persistent pulmonary hypertension, and cyanotic heart disease.

\section{Methods}

The precision and accuracy of $\mathrm{P}_{\mathrm{tcCO}_{2}}$ and $\mathrm{P}_{\mathrm{tcO}}$ were examined at 5 different electrode temperatures $(38,39,40$, 41 , and $42^{\circ} \mathrm{C}$ ) in each infant. All newborns were monitored using 2 transcutaneous monitors applied simultaneously (TCM CombiM, Radiometer, Copenhagen, Denmark). This allowed for one electrode to remain unchanged at $42^{\circ} \mathrm{C}$ (ie, control) while the temperature of the other electrode was randomized to $38,39,40,41$, or $42^{\circ} \mathrm{C}$ (to assure accuracy of the control monitor). The transcutaneous electrodes were applied to the skin of the trunk as recommended by the manufacturer. The accepted standard to which the transcutaneous values were compared was the $\mathrm{P}_{\mathrm{aCO}_{2}}$ and $\mathrm{P}_{\mathrm{aO}_{2}}$. After stabilization of both monitors, 2 arterial blood gases were collected at each temperature, approximately $15 \mathrm{~min}$ apart from an indwelling umbilical arterial catheter (for a total of 10 blood gases). For the purposes of this project, stabilization was defined as a change of $\leq 2 \mathrm{~mm} \mathrm{Hg} \mathrm{P}_{\mathrm{tcCO}_{2}}$ over $5 \mathrm{~min}$. Approximately $0.2 \mathrm{~mL}$ of arterial blood was collected with each sample, which totaled $2 \mathrm{~mL}$ of blood per subject. Total blood collected per subject was recorded during the study. Arterial blood gas sampling and readings of the $\mathrm{P}_{\mathrm{tcCO}_{2}}$ and $\mathrm{P}_{\mathrm{tcO}_{2}}$ levels were performed simultaneously and recorded. After changing the electrode temperature, an appropriate amount of time was allowed for calibration (usually

\section{QUICK LOOK}

\section{Current knowledge}

Transcutaneous monitoring provides continuous $\mathrm{CO}_{2}$ and $\mathrm{O}_{2}$ measurements without the need for blood sampling. Premature infants are at higher risk for complications secondary to abnormal $\mathrm{CO}_{2}$ and $\mathrm{O}_{2}$ levels, therefore continuous monitoring is vital. However, transcutaneous monitoring requires warming of the skin, which has been associated with skin injury in extremely low birthweight infants.

\section{What this paper contributes to our knowledge}

Transcutaneous temperatures as low as $38^{\circ} \mathrm{C}$ provide an accurate assessment of $\mathrm{CO}_{2}$ compared to the previously recommended temperature of $42^{\circ} \mathrm{C}$. Use of lower transcutaneous temperatures to track $\mathrm{CO}_{2}$ trends should allow this technology to be applied in the smallest preterm infants. Transcutaneous monitoring may be useful for tracking $\mathrm{O}_{2}$ levels.

5-10 $\mathrm{min})$ and stabilization of the new electrode temperature (usually 10-15 min). Transcutaneous data were continuously recorded and downloaded from the monitor after the study. The collection of data, per subject, took approximately 4 hours.

\section{Statistical Analysis}

For a sample size estimate, with the design of 5 repeated measurements at each pair of temperatures, a compound symmetry structure was used, and we assumed every pair had the same correlation for within-subject covariance. A sample size of 20 neonates achieved $80 \%$ power to detect a minimum difference of $0.67,0.97$, and 1.2 per standard deviation, respectively, when the correlation between observations on the same subject was $0.1,0.5$, and 0.9 . We used a repeated-measures design for this study, thereby requiring substantially fewer subjects and increasing trial feasibility compared to a 2 -group or $n$-group comparison study.

Summary statistics such as mean and standard deviations were reported. Several comparisons were carried out for the main analysis. Comparison of average $\mathrm{P}_{\mathrm{tcCO}}$ or $\mathrm{P}_{\mathrm{tcO}_{2}}$ between each of the 5 test temperatures and the control temperature were analyzed using repeated-measures analysis of variance followed by Dunnett's method adjusting for multiple comparisons. Comparison of average $\mathrm{P}_{\mathrm{tcCO}}$ or $\mathrm{P}_{\mathrm{tcO}_{2}}$ levels between test temperatures and blood gas measurements, and average warm-up times for stabilization between test temperatures and the con- 
Table 1. Transcutaneous Test Temperatures

\begin{tabular}{|c|c|c|c|c|c|c|c|}
\hline & \multirow{2}{*}{ Temperature } & \multicolumn{3}{|c|}{$\mathrm{P}_{\mathrm{tcCO}_{2}}$} & \multicolumn{3}{|c|}{$\mathrm{P}_{\mathrm{tcO}_{2}}$} \\
\hline & & Mean (SD) & $95 \% \mathrm{CI}$ vs $42^{\circ} \mathrm{C}$ & $P$ & Mean (SD) & $95 \% \mathrm{CI}$ vs $42^{\circ} \mathrm{C}$ & $P$ \\
\hline Control & $42^{\circ} \mathrm{C}$ & $46(5.4)$ & NA & NA & $48(18)$ & NA & NA \\
\hline \multirow[t]{4}{*}{ Test } & $38^{\circ} \mathrm{C}$ & $47(4.1)$ & $(-3.1,5.0)$ & .94 & $31(8.2)$ & $(-26.4,-6.0)$ & .01 \\
\hline & $39^{\circ} \mathrm{C}$ & $47(4.2)$ & $(-3.0,5.0)$ & .93 & $32(7.7)$ & $(-25.9,-5.5)$ & .01 \\
\hline & $40^{\circ} \mathrm{C}$ & $49(6.1)$ & $(-1.1,6.9)$ & .22 & $37(17)$ & $(-20.8,-0.4)$ & .039 \\
\hline & $41^{\circ} \mathrm{C}$ & $47(5.5)$ & $(-2.4,5.7)$ & .70 & $36(11)$ & $(-21.5,-1.1)$ & .030 \\
\hline
\end{tabular}

Comparisons were based on the average values of 2 repeated measurements for each subject.

$\mathrm{NA}=$ not applicable

Table 2. Comparison of Transcutaneous Test Temperatures vs Arterial Value

\begin{tabular}{|c|c|c|c|c|c|c|}
\hline \multirow{2}{*}{$\begin{array}{c}\text { Test } \\
\text { Temperature }\end{array}$} & \multicolumn{3}{|c|}{$\mathrm{CO}_{2}$} & \multicolumn{3}{|c|}{$\mathrm{O}_{2}$} \\
\hline & Transcutaneous Mean (SD) & Arterial Mean (SD) & $P$ & Transcutaneous Mean (SD) & Arterial Mean (SD) & $P$ \\
\hline $38^{\circ} \mathrm{C}$ & $47(4.1)$ & $43(4.4)$ & .01 & $31(8.2)$ & $64(13)$ & .01 \\
\hline $39^{\circ} \mathrm{C}$ & $47(4.2)$ & $42(3.6)$ & $<.001$ & $32(7.7)$ & $63(13)$ & $<.001$ \\
\hline $40^{\circ} \mathrm{C}$ & $49(6.1)$ & $41(3.4)$ & $<.001$ & $37(17)$ & $63(12)$ & $<.001$ \\
\hline $41^{\circ} \mathrm{C}$ & $47(5.5)$ & $43(4.4)$ & $<.001$ & $36(11)$ & $67(11)$ & $<.001$ \\
\hline $42^{\circ} \mathrm{C}$ & $46(5.4)$ & $43(4.7)$ & $<.001$ & $48(18)$ & $64(13)$ & $<.001$ \\
\hline
\end{tabular}

Comparisons were based on the average values of 2 repeated measurements for each subject.

trol temperature were analyzed by testing whether the difference was something other than zero, using the Wilcoxon signed-rank test due to the small sample size. For continuous data, the differences between test and control temperatures were assessed using generalized linear mixed-effect models.

For each neonate, measurements of $\mathrm{P}_{\mathrm{tcCO}_{2}}$ and $\mathrm{P}_{\mathrm{tcO}}$ between the 2 blood gas draws were used for analysis of agreement. Agreement between test and control temperatures, as well as test temperatures versus arterial measurements of $\mathrm{P}_{\mathrm{tcCO}_{2}}$ and $\mathrm{P}_{\mathrm{tcO}}$ was assessed using Bland-Altman plots. Limits of agreements and mean difference were reported. $P$ values $<.05$ indicate statistical significance. All statistical analysis was performed using STATA 14.2 (StataCorp, College Station, Texas) or R v.3.3.2 (R Foundation for Statistical Computing, Vienna, Austria).

\section{Results}

Twenty infants were enrolled. Subject characteristics were (mean $\pm \mathrm{SD}$ ) gestational age $30 \pm 2 \mathrm{wk}$, birthweight $1,449 \pm 304 \mathrm{~g}$, weight at study $1,378 \pm 323 \mathrm{~g}$, and age at study $2 \pm 1 \mathrm{~d}$. $\mathrm{P}_{\mathrm{tcCO}_{2}}$ levels of the control and test sites at $42^{\circ} \mathrm{C}$ were not different $(45.5 \pm 1.0$ vs $45.7 \pm 1.2 \mathrm{~mm} \mathrm{Hg}, P=.87)$. However, $\mathrm{P}_{\mathrm{tcO}_{2}}$ levels of the control and test sites were different $(57.9 \pm 3.2 \mathrm{vs}$ $47.6 \pm 4.0, P=.02$ ). At the time of blood gas analyses, the mean $\mathrm{P}_{\mathrm{tcCO}}$ among all test temperatures versus control $\left(42^{\circ} \mathrm{C}\right)$ were not different, while for $\mathrm{P}_{\mathrm{tcO}}$ there were significant differences between test and control sites for all temperatures (Table 1). The differences between $\mathrm{P}_{\mathrm{tcCO}}$ and $\mathrm{P}_{\mathrm{aCO}}$ values were similar at all temperatures, while $\mathrm{P}_{\mathrm{tcO}}$ values varied markedly with large mean differences compared to blood gas values (Table 2).

Figure 1 shows continuous data for both $\mathrm{P}_{\mathrm{tcCO}}$ and $\mathrm{P}_{\mathrm{tcO}}$ at the lowest test temperature of $38^{\circ} \mathrm{C}$ versus control $\left(42^{\circ} \mathrm{C}\right)$. For $\mathrm{P}_{\mathrm{tcCO}}$, while differences were statistically significant (longitudinal analysis, test of fixed effects, $P=.005$ ), they are not clinically important. For $\mathrm{P}_{\mathrm{tcO}_{2}}$, the difference between $42^{\circ} \mathrm{C}$ versus $38^{\circ} \mathrm{C}$ is quite large. For both $\mathrm{P}_{\mathrm{tcCO}_{2}}$ and $\mathrm{P}_{\mathrm{tcO}_{2}}$, results at $38^{\circ} \mathrm{C}$ aligned well with results at $42^{\circ} \mathrm{C}$. Bland-Altman analysis of $38^{\circ} \mathrm{C}$ versus the control of $42^{\circ} \mathrm{C}$ showed an average bias of 2.2 for $\mathrm{P}_{\mathrm{tcCO}_{2}}$ at $38^{\circ} \mathrm{C}$. Bias is defined as the tendency of a statistic to overestimate or underestimate a parameter. The $95 \%$ limit of agreement is between -7.04 and 11.44, which indicates poor precision (Fig. 2A). Precision refers to how close measurements from different samples are to each other. Results of other test temperatures versus control for $\mathrm{P}_{\mathrm{tcCO}}$ were similar (not shown). Analysis of $\mathrm{P}_{\mathrm{tcCO}}$ versus $\mathrm{P}_{\mathrm{CO}_{2}}$ at $38^{\circ} \mathrm{C}$ showed a positive bias of 4.85 and poor precision with a $95 \%$ limit of agreement between -2.69 and 13.39 (Fig. 2B). For $\mathrm{P}_{\text {tcO }}, 38^{\circ} \mathrm{C}$ versus $42^{\circ} \mathrm{C}$ (Fig. 3A), Bland-Altman analysis showed poor precision and a strong negative bias of -26.1 

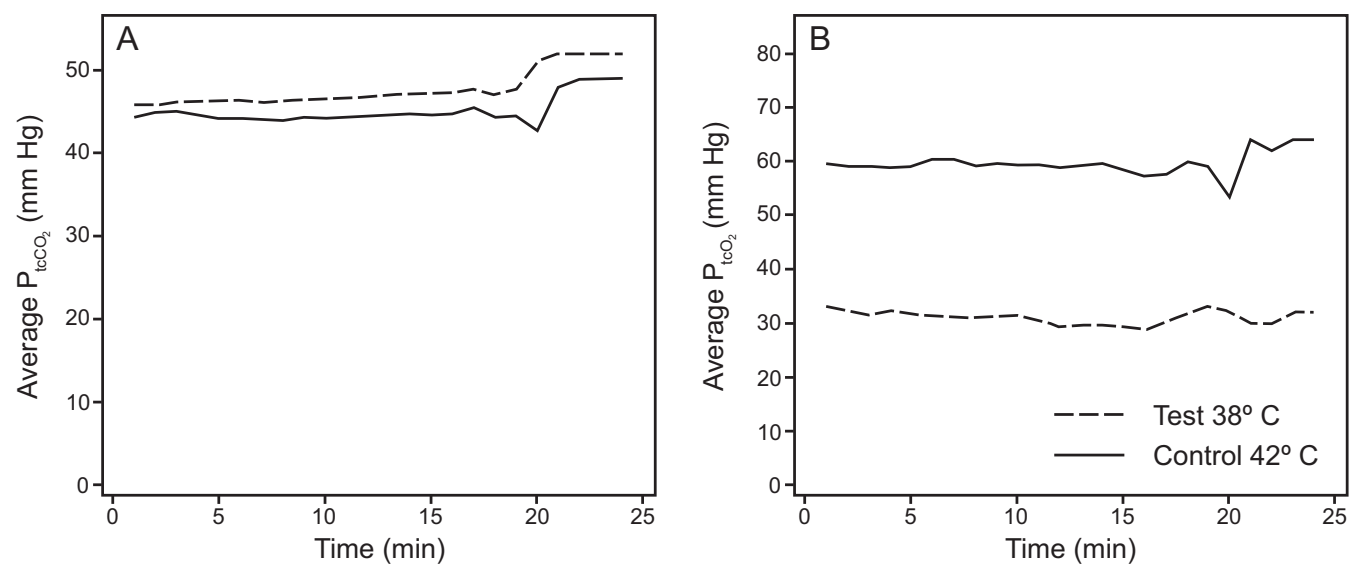

Fig. 1. Continuous data comparing the average $\mathrm{P}_{\mathrm{tcCO}}$ at the lowest test temperature of $38^{\circ} \mathrm{C}$ versus the recommended temperature of $42^{\circ} \mathrm{C}$. The time period shown is between the 2 blood gas draws for each subject at the represented temperatures. Subjects varied in time between blood gas draws. Higher $\mathrm{P}_{\mathrm{tcCO}}$ noted between approximately 20-25 min reflect a smaller $n . P=.005$.
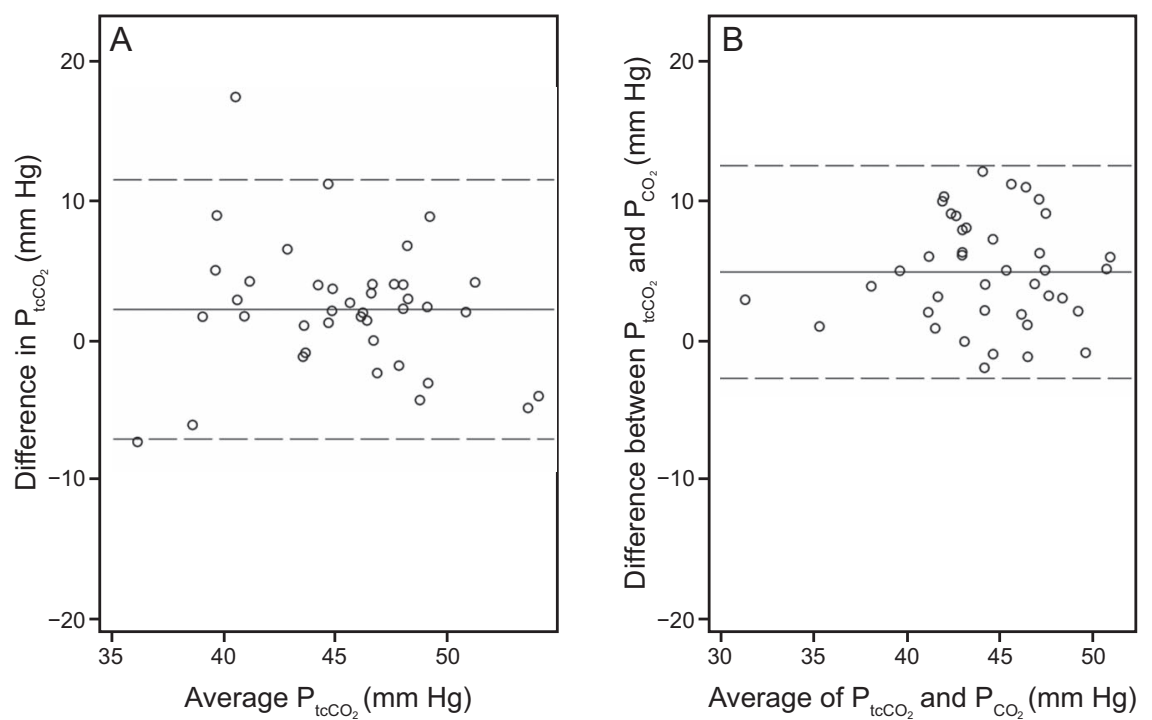

Fig. 2. A: Bland-Altman analysis of $\mathrm{P}_{\mathrm{tcCO}}$ at $38^{\circ} \mathrm{C}$ versus the control of $42^{\circ} \mathrm{C}$. The center horizontal line denotes an average bias of $\mathrm{P}_{\text {tcco }}$ at $38^{\circ} \mathrm{C}$ of 2.2. The $95 \%$ limit of agreement is between -7.04 and 11.44 , which indicates poor precision (indicated by dotted lines showing $\pm 1.96 \mathrm{SD}$ ). B: Bland-Altman analysis of $\mathrm{P}_{\mathrm{tcCO}}$ at $38^{\circ} \mathrm{C}$ versus $\mathrm{P}_{\mathrm{acO}}$. For $\mathrm{P}_{\mathrm{tcCO}}$, there was an average bias of 4.85 (center horizontal line) and poor precision (95\% limit of agreement between -2.69 and 13.39 , indicated by dotted lines showing $\pm 1.96 \mathrm{SD}$ ).

(95\% limit of agreement between -48.51 and -3.61 ). Analysis of $\mathrm{P}_{\mathrm{O}_{2}}$ versus $\mathrm{P}_{\text {tcO }}$ (Fig. 3B) showed a strongly negative bias of -31.85 and poor precision (95\% limit of agreement between -64.05 and 0.35 ). Bland-Altman analysis was done for all test temperatures versus control as well as all temperatures versus $\mathrm{P}_{\mathrm{CO}_{2}}$ and $\mathrm{P}_{\mathrm{O}_{2}}$. Electrode temperature had minimal effect on bias and precision of $\mathrm{P}_{\mathrm{tcO}}$ measurement. However, results of $\mathrm{P}_{\mathrm{tcO}}$ measurements were similar with strong negative biases and poor precision at all test temperatures except for $42^{\circ} \mathrm{C}$. At $42^{\circ} \mathrm{C}$, there was a significantly lower bias and poor precision (Table 3). Time to warm-up for each temperature was not different, ranging from 10.5 to $12.3 \mathrm{~min}$.

\section{Discussion}

Extremes and fluctuations in levels of $\mathrm{CO}_{2}$ and $\mathrm{O}_{2}$ are known to be dangerous and can result in morbidity and mortality for premature infants. The effects of hypercapnia (both permissive and incidental) have been associated with worse neurodevelopmental outcome..$^{4,8-10}$ Hypercapnia is also associated with impaired cerebral autoregulation, leading to an increased incidence of intraventricular hemorrhage. ${ }^{5}$ In fact, extremes and fluctuations in both hypercapnia and hypocapnia are associated with severe intraventricular hemorrhage, especially in the first few days of life. ${ }^{6}$ Not only can over-ventilation damage the 

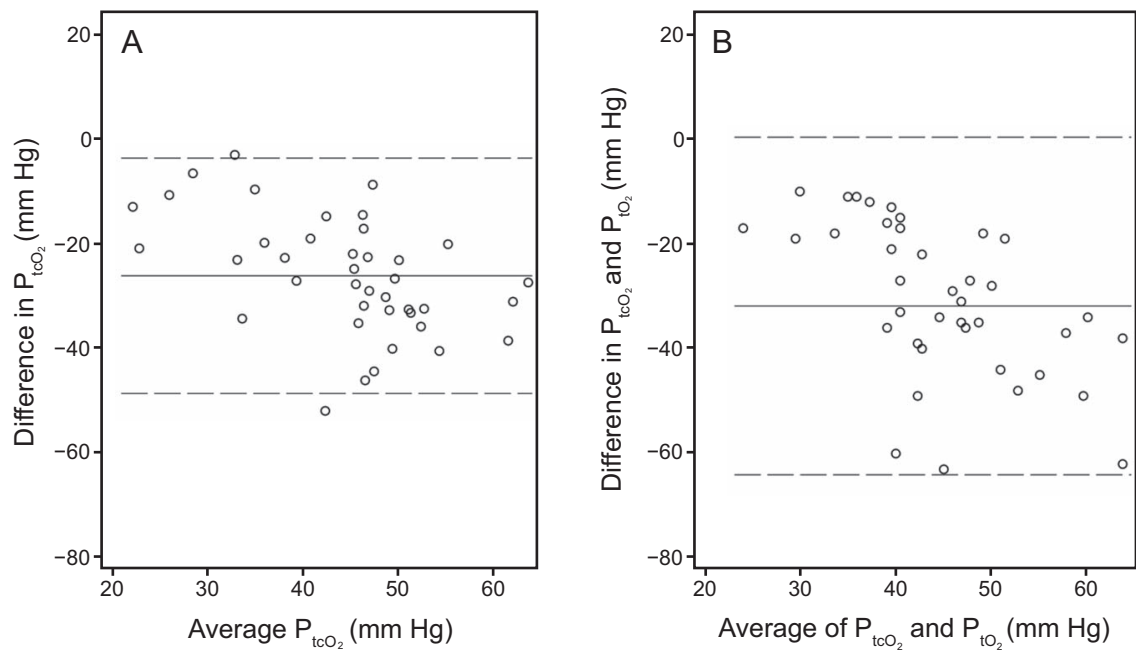

Fig. 3. A: Bland-Altman analysis of $\mathrm{P}_{\mathrm{tcO}}$ at $38^{\circ} \mathrm{C}$ versus the control of $42^{\circ} \mathrm{C}$. Analysis shows poor precision and strong negative bias of -26.1 , shown by the center horizontal line $(95 \%$ limit of agreement between -48.51 and -3.69 , indicated by dotted lines showing $\pm 1.96 \mathrm{SD}$ ). B: Bland-Altman analysis of $\mathrm{P}_{\mathrm{tcO}_{2}}$ at $38^{\circ} \mathrm{C}$ versus $\mathrm{P}_{\mathrm{acO}}$. For $\mathrm{P}_{\mathrm{tcO}}$, there was a strongly negative bias of -31.85 (center horizontal line) and poor precision (95\% limit of agreement between -64.05 and 0.35 , indicated by dotted lines showing \pm 1.96 SD).

Table 3. Bias and Precision for $\mathrm{P}_{\mathrm{tcCO}}$ and $\mathrm{P}_{\mathrm{tcO}}$

\begin{tabular}{|c|c|c|c|c|c|c|}
\hline & \multicolumn{3}{|c|}{$\mathrm{P}_{\mathrm{tcCO}_{2}}$} & \multicolumn{3}{|c|}{$\mathrm{P}_{\mathrm{tcO}_{2}}$} \\
\hline & \multirow{2}{*}{ Bias } & \multicolumn{2}{|c|}{ 95\% Limit of Agreement } & \multirow{2}{*}{ Bias } & \multicolumn{2}{|c|}{ 95\% Limit of Agreement } \\
\hline & & Low & High & & Low & High \\
\hline \multicolumn{7}{|l|}{ Test vs control } \\
\hline $38^{\circ} \mathrm{C}$ vs $42^{\circ} \mathrm{C}$ & 2.20 & -7.04 & 11.44 & -26.10 & -48.51 & -3.69 \\
\hline $39^{\circ} \mathrm{C}$ vs $42^{\circ} \mathrm{C}$ & 1.72 & -8.29 & 11.74 & -27.17 & -48.37 & -5.98 \\
\hline $40^{\circ} \mathrm{C}$ vs $42^{\circ} \mathrm{C}$ & 2.35 & -6.78 & 11.48 & -23.45 & -56.37 & 9.47 \\
\hline $41^{\circ} \mathrm{C}$ vs $42^{\circ} \mathrm{C}$ & 1.47 & -8.93 & 11.88 & -24.37 & -49.15 & 0.40 \\
\hline $42^{\circ} \mathrm{C}$ vs $42^{\circ} \mathrm{C}$ & 0.20 & -10.63 & 11.03 & -10.30 & -48.69 & 28.09 \\
\hline \multicolumn{7}{|l|}{ Test vs arterial } \\
\hline $38^{\circ} \mathrm{C}$ vs arterial & 4.85 & -2.69 & 13.39 & -31.85 & -64.05 & 0.35 \\
\hline $39^{\circ} \mathrm{C}$ vs arterial & 5.50 & -1.76 & 12.76 & -31.13 & -57.77 & -4.48 \\
\hline $40^{\circ} \mathrm{C}$ vs arterial & 6.03 & -3.16 & 15.21 & -30.23 & -70.90 & 10.45 \\
\hline $41^{\circ} \mathrm{C}$ vs arterial & 4.63 & -3.94 & 13.19 & -27.55 & -67.04 & 11.94 \\
\hline $42^{\circ} \mathrm{C}$ vs arterial & 2.93 & -8.16 & 14.01 & -16.53 & -59.69 & 26.64 \\
\hline
\end{tabular}

lung, but hypocapnia has also been found to cause or worsen cerebral ischemia ${ }^{1}$ and is known to be associated with periventricular leukomalacia. ${ }^{2,3}$ Extremes in $\mathrm{O}_{2}$ levels also have negative effects on the neonate. Hyperoxia is associated with periventricular leukomalacia and retinopathy of prematurity, while hypoxia has been shown to cause ischemia and is related to a higher chance of mortality. ${ }^{7}$

Transcutaneous monitoring provides a method to continuously monitor $\mathrm{CO}_{2}$ and $\mathrm{O}_{2}$, and in a recent Cochrane review, Bruschettini et al ${ }^{14}$ called for additional studies demonstrating safety and efficacy in transcutaneous monitoring. More studies are needed to evaluate long-term outcomes of the use of transcutaneous monitoring. There is evidence of earlier diagnosis of pneumothorax prior to decompensation as well as assessment for clinical disease severity in infants with bronchiolitis using continuous transcutaneous monitoring. ${ }^{15,16}$ Transcutaneous monitoring is not the only option for continuous monitoring of $\mathrm{CO}_{2}$ and $\mathrm{O}_{2}$, but at this time it is the most useful. End-tidal $\mathrm{CO}_{2}$ monitoring has been used, but there are documented disadvantages to end-tidal monitoring that make it less feasible in the neonate. In infants with lung disease, who comprise a large proportion of neonatal subjects, ventilation-perfusion mismatch can lead to inaccurate results. Most neonates have a high breathing frequency requiring a faster response time than end-tidal sensors can deliver. This population also has a lower tidal volume resulting in proportionally increased dead 
space of the sensors. In addition, end-tidal monitoring can underestimate $\mathrm{CO}_{2}$ levels. ${ }^{17-19}$ Monitoring end-tidal $\mathrm{CO}_{2}$ at the distal end of a double-lumen endotracheal tube may be useful, but these tubes are not always used for neonates. ${ }^{20}$ Given these issues, transcutaneous monitoring is the best option at this time for continuous $\mathrm{CO}_{2}$ monitoring.

To measure $\mathrm{O}_{2}$ saturation, the modality used most frequently is pulse oximetry $\left(\mathrm{S}_{\mathrm{pO}_{2}}\right)$. $\mathrm{S}_{\mathrm{pO}_{2}}$ is widely available and easy to use, but it has weaknesses as well. Due to the $\mathrm{O}_{2}$-dissociation curve, $\mathrm{S}_{\mathrm{pO}_{2}}$ is unable to provide accurate estimates of $\mathrm{P}_{\mathrm{O}_{2}}$ levels at higher $\mathrm{O}_{2}$ saturation levels, which may be associated with very high $\mathrm{P}_{\mathrm{O}_{2}}$, which is harmful to the infant. ${ }^{21,22}$ Continuous accurate monitoring of $\mathrm{P}_{\mathrm{O}_{2}}$ could be useful to avoid hyperoxia and hypoxia. Infants with pulmonary hypertension and infants of extremely low birthweight are examples of subjects in whom very close monitoring of $\mathrm{P}_{\mathrm{aO}_{2}}$ levels could be especially useful. It may be of more limited use in extremely premature infants, given their lower oxygenation targets. In our study, wide differences in $\mathrm{P}_{\mathrm{tcO}_{2}}$ and $\mathrm{P}_{\mathrm{aO}}$ occurred, even at $42^{\circ} \mathrm{C}$. As noted above, there were also electrode-site differences for $\mathrm{P}_{\mathrm{tcO}}$. Because arterialization of the capillary bed is so important for $\mathrm{P}_{\mathrm{tcO}_{2}}$ monitoring, perhaps a higher electrode temperature is required to accurately assess $\mathrm{P}_{\mathrm{tcO}}$ trends. Transcutaneous monitoring may have an important role in continuous $\mathrm{P}_{\mathrm{O}_{2}}$ assessment in larger infants who can tolerate higher electrode temperatures, and its use should perhaps be re-evaluated, particularly in the setting of pulmonary hypertension.

In our study, we assessed both $\mathrm{P}_{\mathrm{tcCO}_{2}}$ and $\mathrm{P}_{\mathrm{tcO}}$ at the recommended electrode temperature of $42^{\circ} \mathrm{C}$ and at several lower temperatures. We found that electrode temperatures as low as $38^{\circ} \mathrm{C}$ provide an accurate assessment of $\mathrm{P}_{\mathrm{CO}_{2}}$ and similar trends compared to the recommended electrode temperature of $42^{\circ} \mathrm{C}$. In comparison to the accepted standard of arterial blood gas measurement, transcutaneous electrode temperatures were accurate at every test temperature $\left(38,39,40,41\right.$, and $\left.42^{\circ} \mathrm{C}\right)$, with mean differences from arterial values ranging from 2 to $8 \mathrm{~mm} \mathrm{Hg}$.

Using an older transcutaneous monitor, Sorensen et al ${ }^{13}$ found that electrode temperatures of 40 and $41^{\circ} \mathrm{C}$ could be used to track $\mathrm{P}_{\mathrm{tcCO}_{2}}$; they recommend, however, using a correction factor of $12-15 \%$. More recently, Hirata et al ${ }^{23}$ found results similar to ours with electrode temperatures of 38,39 , and $40^{\circ} \mathrm{C}$ in comparison to a control of $42^{\circ} \mathrm{C}$, but they recommended a correction factor of $6 \mathrm{~mm} \mathrm{Hg}$. Hirata et al, ${ }^{23}$ however, did not use 2 monitors simultaneously, which is a major strength of our study. Given our average difference of $2.2 \mathrm{~mm} \mathrm{Hg}$ between $38^{\circ} \mathrm{C}$ and $42^{\circ} \mathrm{C}$, we do not feel a correction factor is needed, although occasional correlation with an arterial gas must be done. It is important to note that the limit of agreement in the neonate between arterial and transcutaneous values may be more dependent on skin perfusion due to blood flow changes in the neonatal skin. The trend in any one infant is more important than the absolute difference between the transcutaneous reading and the arterial value, therefore it may be more important to be aware of trends than to use a correction factor.

For $\mathrm{P}_{\mathrm{tcO}_{2}}$, transcutaneous monitoring has been associated with skin burns as well as measurement inaccuracies at lower electrode temperatures. For accurate measurement of $\mathrm{P}_{\mathrm{O}_{2}}$ trends, transcutaneous monitoring requires an electrode temperature sufficient for arterialization of the capillary bed. ${ }^{13,24}$ In our study we reassessed $\mathrm{P}_{\mathrm{tcO}}$ using newer electrode technology recently developed by Radiometer (Copenhagen, Denmark). We tested this technology to assess any improvements in $\mathrm{P}_{\mathrm{tcO}_{2}}$ measurements. The new sensors reportedly have a very small surface and a site time-heat function monitor that ensures that the heating of the sensor is automatically switched off after a monitoring session, theoretically decreasing the risk of skin damage. We found that while $\mathrm{P}_{\mathrm{tcO}}$ values were much lower than arterial values, especially at low electrode temperatures, $\mathrm{P}_{\mathrm{tcO}_{2}}$ appeared to track the higher electrode temperature results relatively well. Thus, following both $\mathrm{P}_{\mathrm{tcO}}$ and $\mathrm{P}_{\mathrm{tcCO}_{2}}$ may be clinically useful, even when low electrode temperatures are employed.

\section{Limitations}

This was a small study with an enrollment of 20 subjects. We did not include babies with birthweight of $<1 \mathrm{~kg}$ due to the potential of skin burns in this population at the higher electrode temperatures. The majority of our infants required only minimal respiratory support, and the study was short in duration, lasting approximately $4-5 \mathrm{~h}$. It is also worth noting that, in general, the monitor performed with limited precision, likely due to changes in perfusion. For this reason, we recommend occasional correlation with an arterial blood gas.

\section{Conclusions}

Continuous $\mathrm{CO}_{2}$ and $\mathrm{O}_{2}$ monitoring are of utmost importance in extremely premature infants. Our results support and expand current literature. Use of transcutaneous monitor temperatures as low as $38^{\circ} \mathrm{C}$ allow accurate monitoring and tracking of $\mathrm{P}_{\mathrm{CO}_{2}}$ and therefore can be used instead of the recommended $42^{\circ} \mathrm{C}$. For $\mathrm{P}_{\mathrm{O}_{2}}$, transcutaneous monitoring may be useful for trending, although caution must be used in the interpretation of $\mathrm{P}_{\mathrm{tcO}_{2}}$ values. Use of lower transcutaneous temperatures to track $\mathrm{P}_{\mathrm{CO}_{2}}$ values should allow this technology to be applied in the smallest preterm infants.

\section{REFERENCES}

1. Curley G, Kavanagh BP, Laffey JG. Hypocapnia and the injured brain: Evidence for harm. Crit Care Med 2011;39(1):229-230. 


\section{Transcutaneous Electrode Temperatures in Preterm Infants}

2. Wiswell TE, Graziani LJ, Kornhauser MS, Stanley C, Merton DA, McKee L, et al. Effects of hypocarbia on the development of cystic periventricular leukomalacia in premature infants treated with highfrequency jet ventilation. Pediatrics 1996;98(5):918-924.

3. Zhou W, Liu W. Hypercapnia and hypocapnia in neonates. World J Pediatr 2008;4(3):192-196.

4. Altaany D, Natarajan G, Gupta D, Zidan M, Chawla S. Severe intraventricular hemorrhage in extremely premature infants: Are high carbon dioxide pressure or fluctuations the culprit? Am J Perinatol 2015;32(9):839-844.

5. Kaiser JR, Gauss CH, Pont MM, Williams DK. Hypercapnia during the first 3 days of life is associated with severe intraventricular hemorrhage in very low birth weight infants. J Perinatol 2006;26(5): 279-285.

6. Fabres J, Carlo WA, Phillips V, Howard G, Ambalavanan N. Both extremes of arterial carbon dioxide pressure and the magnitude of fluctuations in arterial carbon dioxide pressure are associated with severe intraventricular hemorrhage in preterm infants. Pediatrics 2007;119(2):299-305.

7. Askie LM, Darlow BA, Davis PG, Finer N, Stenson B, Vento M, Whyte R. Effects of targeting lower versus higher arterial oxygen saturations on death or disability in preterm infants. Cochrane Database Syst Rev 2017;4:CD011190.

8. Thome UH, Carroll W, Wu TJ, Johnson RB, Roane C, Young D, et al. Outcome of extremely preterm infants randomized at birth to different $\mathrm{PaCO} 2$ targets during the first seven days of life. Biol Neonate 2006;90(4):218-225.

9. Ambalavanan N, Carlo WA, Wrage LA, Das A, Laughon M, Cotten $\mathrm{CM}$, et al. $\mathrm{PaCO} 2$ in surfactant, positive pressure, and oxygenation randomised trial (SUPPORT). Arch Dis Child Fetal Neonatal Ed 2015;100(2):F145-F149.

10. McKee LA, Fabres J, Howard G, Peralta-Carcelen M, Carlo WA, Ambalavanan $\mathrm{N}$. PaCO2 and neurodevelopment in extremely low birth weight infants. J Pediatr 2009;155(2):217-221.

11. Aliwalas LL, Noble L, Nesbitt K, Fallah S, Shah V, Shah PS. Agreement of carbon dioxide levels measured by arterial, transcutaneous and end tidal methods in preterm infants $<$ or $=28$ weeks gestation. J Perinatol 2005;25(1):26-29.

12. Thomas PE. What's the latest on carbon dioxide monitoring? Neonatal Netw 2004;23(4):70-72.
13. Sorensen LC, Brage-Andersen L, Greisen G. Effects of the transcutaneous electrode temperature on the accuracy of transcutaneous carbon dioxide tension. Scand J Clin Lab Invest 2011;71(7):548-552.

14. Bruschettini M, Romantsik O, Zappettini S, Ramenghi LA, Calevo MG. Transcutaneous carbon dioxide monitoring for the prevention of neonatal morbidity and mortality. Cochrane Database Syst Rev 2016;2:CD011494.

15. McIntosh N, Becher JC, Cunningham S, Stenson B, Laing IA, Lyon $\mathrm{AJ}$, et al. Clinical diagnosis of pneumothorax is late: use of trend data and decision support might allow preclinical detection. Pediatr Res 2000;48(3):408-415.

16. Gal S, Riskin A, Chistyakov I, Shifman N, Srugo I, Kugelman A. Transcutaneous PCO2 monitoring in infants hospitalized with viral bronchiolitis. Eur J Pediatr 2015;174(3):319-324.

17. Tingay DG, Mun KS, Perkins EJ. End tidal carbon dioxide is as reliable as transcutaneous monitoring in ventilated postsurgical neonates. Arch Dis Child Fetal Neonatal Ed 2013;98(2):F161-F164.

18. Tingay DG, Stewart MJ, Morley CJ. Monitoring of end tidal carbon dioxide and transcutaneous carbon dioxide during neonatal transport. Arch Dis Child Fetal Neonatal Ed 2005;90(6):F523-F526.

19. Schmalisch G. Current methodological and technical limitations of time and volumetric capnography in newborns. Biomed Eng Online 2016;15(1):104

20. Kugelman A, Golan A, Riskin A, Shoris I, Ronen M, Qumqam N, et al. Impact of continuous capnography in ventilated neonates: A randomized, multicenter study. J Pediatr 2015;168:56-61.

21. Quine D, Stenson BJ. Does the monitoring method influence stability of oxygenation in preterm infants? A randomised crossover study of saturation versus transcutaneous monitoring. Arch Dis Child Fetal Neonatal Ed 2008;93(5):F347-F350.

22. Lakshminrusimha S, Manja V, Mathew B, Suresh GK. Oxygen targeting in preterm infants: a physiological interpretation. J Perinatol 2015;35(1):8-15.

23. Hirata K, Nishihara M, Oshima Y, Hirano S, Kitajima H. Application of transcutaneous carbon dioxide tension monitoring with low electrode temperatures in premature infants in the early postnatal period. Am J Perinatol 2014;31(5):435-440.

24. Poets CF, Bassler D. Providing stability in oxygenation for preterm infants: Is transcutaneous oxygen monitoring really better than pulse oximetry? Arch Dis Child Fetal Neonatal Ed 2008; 93(5):F330-F331. 